\title{
Hypnosis as a way of spending of general anesthesia.
}

\author{
Shaposhnikov Veniamin Ivanovich* \\ Kuban Medical Institute, Professor of surgical diseases, Vice Rector, Krasnodar, Russia
}

\begin{abstract}
This article contains a surveillance operation on the foot bone-plastic holding a child 5 years under hypnosis. By the nature of the selected general anesthesia work should be attributed to the category of fantasy, but the author Dick MOAN, academician of RAE, a member of the EA, Professor and doctor of medical sciences, i.e. deserves due attention to himself and to his work. Article is very kazuisticheskih, but real events and described, so lets take a look at the human mental activities from a new perspective. When accumulating clinical experience, and performing operations under hypnosis, without a doubt, conducted and other surgeons will make on this issue, certain theoretical and practical conclusions.
\end{abstract}

Keywords: Hypnosis, General anesthesia, Operation recovery.

\section{Introduction}

Hypnosis (sleep) has been known since ancient times. Its main aim is to introduce a person in a State of catalepsy when he does not react to light, pain, coldness, and in so doing performs various guidance against his will [1,2]. Most often it is used for treating depression, anxiety and other neurotic conditions [1]. It sought refusal from smoking, drugs, alcohol and gluttony $[3,4]$. These studies contribute to widespread dissemination of modern views on hypnosis as a means of correction of the mental status of a person. It finds application in clinical practice [5]. For example, in recent decades, there is evidence of the use of hypnosis and in surgical interventions. Describes the programmer of hypnotic treatment with decreased pain when carrying out surgical and dental operations [6,7]. However, the question of the use of hypnosis as a method for the production of general anesthesia is still under study. For this reason each clinical observation on this topic deserves attention.

\section{Materials and Methods}

On the feasibility of the application of hypnosis in surgery, I found personally during his surgical activity. It was 40 years ago. Once in Office 5-year-old girl has appeared with enhondromoy main phalanx I metatarsal bone left foot, which was causing child pain when walking. Radiographically, it was found that swelling is enhondromoy, and it has begun already to destroy this cortical bone, i.e. clearly has for malignant neoplasm. The mother appealed to many children's medical institution in the country, but when the survey she has identified severe allergic rhinitis. It is not clear all known drugs used for general and local anesthesia. The allergy twice had nearly ended by the death of the patient. After the last treatment failure, local doctors advised mothers appeal to me. While studying history at this girl, it became clear that the operation requires a typical kind of general anesthesia, and in this situation to them belonged only to hypnosis. I informed the mother, but warned that, although I know the technology, but the surgeon by profession, not a psychiatrist. For this reason, I promise nothing in advanceI'll try to introduce a girl into hypnosis, and then perform kostnoplasticheskuju operation, taking a grant from the iliac wing bone.

Before the start of the hypnotism Act held a briefing with staff of the Office, which they behave quietly and did not engage in conversation with me and with the patient. Then the child was taken to the operating room. Relatively easy it was introduced into hypnosis by traditional methods. An incision was made on the finger. Fully implemented nucleation of the tumor. The graft is taken from the iliac crest and embedded in the bone cavities formed on the finger. Bone chips in her crammed all cracks. The duration of all the manipulation was 40-45 mins. After implementation of plastics and layer-by-layer closure of wound on his finger began to overlap seams on a wound in the area of the ileum. During all these manipulations, the child was lying motionless and did not issue any sound. Quietly behaved operating sister and aide. And that's when I overlaid the last seam, aide leaned in to face the girl and whispered: "say, Babe, and you don't get hurt!?" the patient immediately woke up and feeling the pain, yelled, but the operation was already over. Thus, he saved me from output of patient labour of catalepsy.

\section{Results}

During the Post-operative patients went without complications. What happened during the surgical procedure, she is absolutely not remembered, but the pain is not experienced. The patient was discharged from office through the 40 days. During this time produced milestone x-rays that revealed the closure of the former cavity, which before was enhondromoy. Her mental problems were observed. The delay can be attributed to the office girls clinical interest.

\section{Discussion}

Primenjonnuju technique with General anesthesia, the patient, can be regarded as successful. It fully meets and confirms the modern views on hypnosis as a means of rack and secures the correction of pain when performing surgery. This is especially important happens when conventional means to apply general anesthesia is dangerous-such as for allergies to 
him that it was in the observation. Hypnosis had enabled run the child urgently needed surgery. Thus, in exceptional cases it can be used in clinical practice for pain relief.

\section{Conclusion}

In cases of extreme necessity as a means of general anesthesia can use hypnosis, but this technique requires careful study, to collective labor of surgeons and psychiatrists to determine the advantages and disadvantages of this method in clinical practice. One only, it is clear that this method is worthy of study and application.

\section{References}

1. Kandyba VM. Hypnosis and disease. Basics of hypnotherapy. Encyclopedia of the best world experience. Lan. 2003.
2. Dave E. Hypnotherapy. Psychotherap. 2014.

3. Anna A. Instant hypnosis. How does the power of suggestion work. Book Club. 2014.

4. Khamidova VR. Hypnotic manipulations. Manipulations of subconscious. Ripol Classic. 2007.

5. Nord N. The Secret techniques of modern hypnosis. Tsentrpoligraf. 2010.

6. Lynn S, Kirsch I. The basics of clinical hypnosis. Essentials of clinical hypnosis: An evidence-based approach. Publishing House of the Institute of Psychotherapy. 2011.

7. Tukaev RD. Hypnosis. Mechanisms and methods of clinical hypnotherapy. Medical Information Agency. 2006.

\section{*Correspondence to:}

Shaposhnikov Veniamin Ivanovich, MD, Professor, Kuban Medical Institute, Professor of hospital surgery,

St. 40 let Pobedy 33/8 kV. 193, Krasnodar, 350072, Russia

Tel- 89183446404

E-mail-Shaposhnikov35@Mail.ru 